Viewpoint

\title{
Why One Has to Be Vegetarian?
}

\author{
Namra Kr. Mahato
}

BPH $23^{\text {rd }}$ Batch

Nowadays vegetarian diet has become extremely popular all over the world. A number of people prefer vegetarian diet. Actually it is considered that a vegetarian diet represents a key point to health. ${ }^{(1)}$ According to the Vegetarian society in UK, $9 \%$ of the population in UK and US are complete vegetarians with the number constantly increasing. (2)

\section{"What is a vegetarian?}

There are roughly three types of vegetarian.

Vegans or strict vegetarians exclude all animal products (e.g. meat, poultry, fish, eggs, milk, cheese, and other dairy products). Many vegans also do not eat honey.

Lactovegeterians exclude meat, poultry, fish and eggs but include dairy products.

Lacto-ovovegetarians exclude meat, poultry, and fish but include dairy products and eggs. Most vegetarians in the US are lacto-ovovegetarians."(3)

\section{Advantages of being Vegetarian}

\section{Health advantages}

The first of these advantages include the benefits reaped from better health. Becoming a vegetarian is one of the best things that you can do for your body. There is less chance of being overweight and there is healthier glow/clearer complexion. Fruits, vegetables and nuts contain the necessary minerals and nutrients for your body to properly function. While meats contain helpful compounds, including certain types of acids and protein, it is possible to acquire all of the necessary nutrients without eating any animal products. ${ }^{(4)}$ Plant sources of protein alone can provide adequate amounts of essential amino acids if a variety of plant foods are consumed and energy needs are met. ${ }^{(2)}$ Fish oil is a common source of Omega 3 essential fatty acids, but flaxseed and flaxseed oil contain even greater quantities of it. ${ }^{(6)}$ More fruits and vegetables mean more vitamins for you. Less meat means fewer toxins and unwanted hormones in your body. Your immune system will greatly improve after replacing meat with more greens.

Results of different studies show that people who follow a vegetarian diet have lower risk of several diseases like cancer (e.g colorectal cancer, breast cancer), heart problem, blood pressure, diabetes and strokes. In fact, Vegetarian diets low in fat or saturated fat have been used successfully as part of comprehensive health programs to reverse severe coronary artery disease. ${ }^{(2,7)}$
Cardiovascular disease is often connected with a diet full of saturated fats and cholesterol from meat. The average person eating a meat-based diet has $50 \%$ chance of dying from a heart disease. If he go vegetarian this decrease to $15 \%$

At age 65 , the average woman has a bone loss of 35\%. A vegetarian woman has an average loss of $18 \%$, at the age of 65 . This is because a non-vegetarian gets excessively much protein. At overage, meat eaters get about $150 \%$ more protein each day than they need. Vegetarian diet safeguards against osteoporosis. Also the lower estrogen levels in vegetarian women provide higher benefits.

A well-planned vegetarian diet may be useful in the prevention and treatment of renal disease. Studies using human being and animal models suggest that some plant proteins may increase survival rates and decrease proteinuria, glomerular filtration rate, renal blood flow and histologic renal damage compared with a non-vegetarian diet.

Vegetarianism protects you from certain food-borne diseases such as bird flu, mad cow disease, intestinal parasites, etc.

According to the American Dietetic Association, "Vegetarian diets offer a number of nutritional benefits, including lower levels of saturated fat, cholesterol....... as well as higher levels of carbohydrates, fiber, magnesium, potassium, folate, and antioxidants such as vitamins $\mathrm{C}$ and E and phytochemicals."(6)

Meat is difficult for the body to digest and may putrefy especially for those who don't have an active lifestyle, as it stays in the stomach for longer. On the other hand, different vegetarian diets are easy to digest, it makes blood sugar more stable, your energy level will be consistent and you will not get that fatigue feeling after meals. ${ }^{(7)}$

You'll eat fewer chemicals lower on the food chain. The more chemicals an animal eats, the more you will eat. It can be clearly understood from the concept of bioaccumulation and biomagnifications. Bio-accumulation is increase in the concentration of the chemical substances in an organism or a part of the organism. Bio-magnification is increase in the concentration of chemical substances in food chain; it increases about $10 \%$ in each tropic level. The primary source of nuclear radiation contamination in humans is from beef and dairy products. ${ }^{(8)}$

Approximately 30 percent of slaughtered chicken and fish 
is contaminated with salmonella. It sickens between 6.5 and 8 million people each year in the US. E.coli, salmonella and campylobacter bacteria causing food poisoning in restaurants are usually from animal products that are not cooked properly, have been sitting too long before being served, ${ }^{(8)}$

In 1997, the World Cancer Research Fund (WCRF) and the American Institute of Cancer Research (AICR) commissioned a panel of experts from twenty countries to examine the available evidence on the diet and cancer connection. In its conclusion it says, various studies have shown that groups following lacto-ovo, lacto-vegetarian and vegan diets have decreased incidence of cancers at several specific sites. Any effect of vegetarian diets is likely to be due not only to the exclusion of meat, but also due to the inclusion of a larger number and wider range of plant foods containing an extensive variety of potential cancerpreventive substances. ${ }^{(9)}$

\section{The Disadvantages of Eating Meat}

"There are many physical disadvantages to eating meat. Some of these disadvantages are:

1. A meat-eater not only takes in the animal cells and fats, etc. but also the waste products, e.g. chemically treated food fed to the animals, drugs injected into the animal in the slaughter house, intoxicants, coloring and tenderizers sprayed on the dead animal by the market suppliers.

2. Meat is one of the major sources of internal pollution. When an animal is slaughtered, un-eliminated waste products remain in the tissue of the animal which often give the meat its stimulating flavor. Uric acid and adrenaline are secreted into the bloodstream, muscles of animals and stored. The fear and struggle to escape death stimulates the secretion of hormones like epinephrine and norepinephrine. Most animals (especially cows) are injected with steroids before they are slaughtered. No edible plant product has similar toxicity. The human body has to work 15 times more to get rid of these toxins.

3. A parasite known for inducing miscarriage, blindness, jaundice and nervous disorders in newborn babies was found in samples of animal meat from abattoirs and markets (particularly in third world countries).

4. To preserve fish and prawns and other crustaceans, boric acid is widely used by food manufacturers. It attacks the liver and the brain, causing fits and coma before the victim dies of liver damage. Fruits and vegetables, however heavily sprayed, don't grow hormones, antibiotics and other drugs common in meat products.

5. Pigs carry trichinosis bacteria that cling to the walls of the stomach and intestines, which can be fatal. Beef and pork are highly acid forming and release into the blood-stream toxic poisons and microbes."(2)

\section{Spiritual advantages}

It is said that different food types embody different vibrations and there is animals' consciousness in meat that is aggressive and restless and when meat of these animals is taken, their traits transfer to the person who consumes it. Contrarily, vegetarian foods do not provoke aggression and restlessness in the eaters. Remember that you are what you eat. The food taken into your body is what gradually but surely forms your thought-patterns. ${ }^{(2,7)}$

Many religions like Buddhism, Hinduism, Jainism, etc believe that the vegetarian diet is necessary component for meditation and attaining God. They believe in non violence.

\section{Animal Welfare}

No animal is harmed in order to feed or clothe a vegetarian. As more people become vegetarian, farming and the meat production industry will change. ${ }^{(10)}$

\section{Environmental Issues}

Real environmental benefits can be realized by people reducing their consumption of meat or becoming a vegetarian. The GoVeg website quotes Environmental Defense that reports that "if every American skipped one meal of chicken per week and substituted vegetarian foods instead, the carbon dioxide savings would be the same as taking more than a half-million cars off U.S. roads".(10)

Producing vegetarian foods is a lot easier than looking after livestock, as it requires a higher percentage of land space and attention to give. ${ }^{(7)}$ If everyone in North America reduced their animal food consumption by just 10 percent, the grain we would save from animal feed could be used to feed all of the hungry throughout the world (Earth Save). Poultry operations alone use 96.5 billion gallons of water annually in the US, enough to meet all water needs of 4.5 million North Americans.

\section{Budget}

A person leading a vegetarian lifestyle can spend much less than their meat eating counterparts. Vegetarian food is often cheaper, this includes both the raw ingredients purchased from supermarkets and meals taken in restaurants and other eateries. Meat makes up a significant proportion of a typical household food bill. By taking meat from the equation, a large saving can be had. Of course, replacing meat with expensive vegetarian meat substitutes may not result in quite the same saving. If a household, however, replaces meat with lentils and other low cost forms of nutritious and natural foods, a greater saving will be realized. ${ }^{(10)}$

\section{Conclusion}

So it's quite clear from above description that being a vegetarian not only protects but also prevents us from several chronic and acute diseases. Be it from the spiritual, moral, energy or environmental point of view, its always 
better to be vegetarian. We are sensible creatures so lets not compromise our well being for just taste, that too can be obtained from veggie diet.

There are really no disadvantages of being a vegetarian, only challenges. ${ }^{(3)}$

\section{References}

1. Nina Nik.Health goes up,advantages and disadvantages of being vegetarian[Internet].2010 Apr 22 [cited 2011 sep 19]. Available from: http:// www.healthgoesup.com/articles/418/1/advantagesand-disadvantages-of-being-vegetarian-1.html

2. The physical advantages of being vegetarian [Internet].2011 [cited 2011 sep 19]. Available from: http://www.celestialhealing.net/physicalveg.htm

3. Isak Ravn. Associated content from yahoo, What are the benefits and disadvantages of being vegetarian.[Internet].2009 Mar 12[cited 2011 Sep 19].Available from: http:// www.associatedcontent.com/article/1543115/ what_are_the_benefits_and_disadvantage.html?cat=22

4. Vegetarian junction, The advantages of a vegetarian diet.[Internet]. 2011 Apr 22 [cited 2011 sep 19]. Available from: http://www.vegetarianjunction.com/ becoming-vegetarian/advantages-of-vegetarian-diet/

5. Methods of healing, disadvantages of being a vegetarian. [Internet].2009 Mar 16 [cited 2011 sep 19]. Available from: http://www.methodsofhealing.com/ disadvantages-of-being-a-vegetarian/

6. Mukherjee Nita. Associated content from yahoo, Health and other benefits of a vegetarian diet. [Internet].2009 Jul 22 [cited 2011 Sep 19]. Available from: http://www.associatedcontent.com/article/ $1971866 /$ health_ and_other_ benefits_of_a vegetarian_pg3.html?cat=5

7. All health site, Advantages and disadvantages of being a vegetarian. [Internet]. [cited 2011 sep 19].Available from: http://www.allhealthsite.com/ advantages - and-dis advantages-of-beingvegetarian.html

8. Crenna Carol. People with compassion, 30 reasons to become vegetarian. [Internet]. [cited 2011 sep 19].Available from: http://animalrightsinfo.tripod.com/ id22.html

9. Vegetarian diet plans, Advantages of being a vegetarian.[Internet].2011 Jun 12 [cited 2011 sep 19]. Available from: http://www.vegetariandietplans.net/ nutrition/advantages-of-being-a-vegetarian.htm

10. Pullen Kate. Love to know vegetarian, Advantages of being vegetarianism. [Internet]. [cited 2011 sep
19].Available from: http://vegetarian.lovetoknow.com/ Advantages_of_Vegetarianism 